\section{Severe gastric ischemia after combined sclerotherapy for bleeding gastric ulcer}

The choice of type of additional endoscopic therapy after epinephrine injection for bleeding peptic ulcers should be carefully individualized according to the characteristics of the ulcer.

A 56-year-old man with diabetes mellitus was admitted with a 24-hour history of hematemesis and melena. On physical examination, his blood arterial pressure was $100 / 60 \mathrm{mmHg}$ and heart rate $120 / \mathrm{min}$. The hemoglobin level was $10.8 \mathrm{~g} / \mathrm{dL}$. Endoscopy showed fresh blood in the stomach and a 12-mm ulcer in the antrum with active oozing bleeding from a flat visible vessel (Forrest Ib classification). Injection of $8 \mathrm{~mL}$ of epinephrine (1/10000 solution) on the edges of the ulcer did not stop

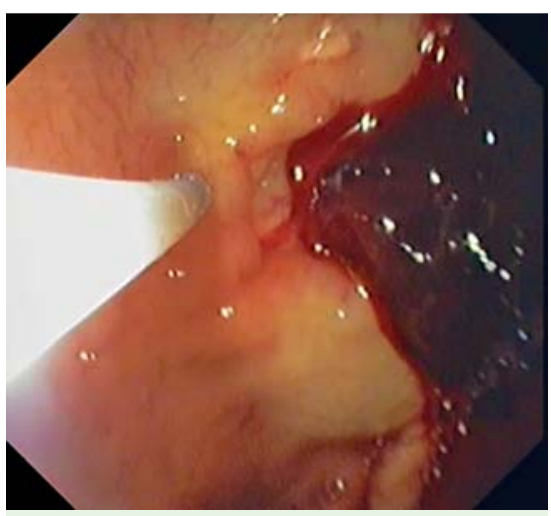

Fig. 1 Epinephrine injection on the edges of a gastric ulcer with active oozing bleeding.

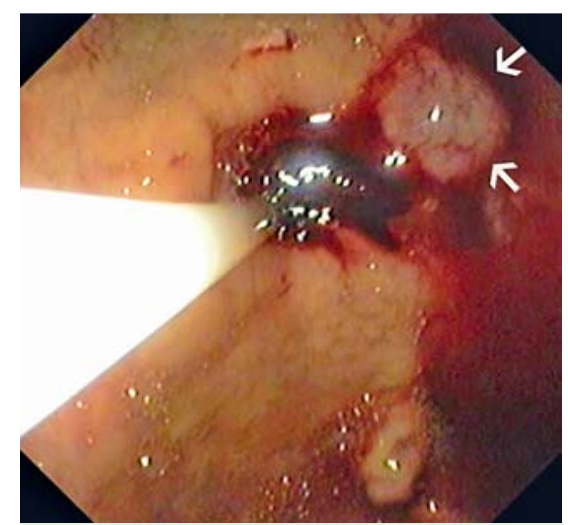

Fig. 2 Immediately after injecting ethanolamine oleate, a purplish protruding lesion (arrows) appeared besides the ulcer, indicating vascular injury. bleeding ( Fig. 1). Consequently, sclerotherapy with ethanolamine oleate (EO) was carried out and, immediately after injection of $1.5 \mathrm{~mL}$ a purplish protruding lesion appeared besides the ulcer ( $\bullet$ Fig. 2 ), which prevented the endoscopist from further administering EO. Hemostasis was successfully achieved after combined sclerotherapy ( Fig. 3). After $48 \mathrm{~h}$, the patient experienced abdominal pain and severe re-bleeding. Endoscopy revealed a deep ulcer covering half of the surface of the distal antrum ( $\bullet$ Fig. 4). Emergency vascular computed tomography ruled out arterial thrombosis. The patient was discharged after proton pump inhibitor perfusion and wide spectrum antibiotherapy

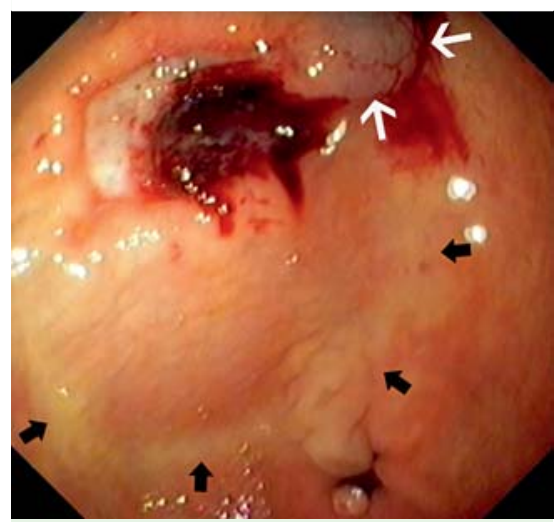

Fig. 3 Final hemostasis at the ulcer after combined sclerotherapy, with the vascular lesion (white arrows) and a remarkable swollen ischemic ring (black arrows).

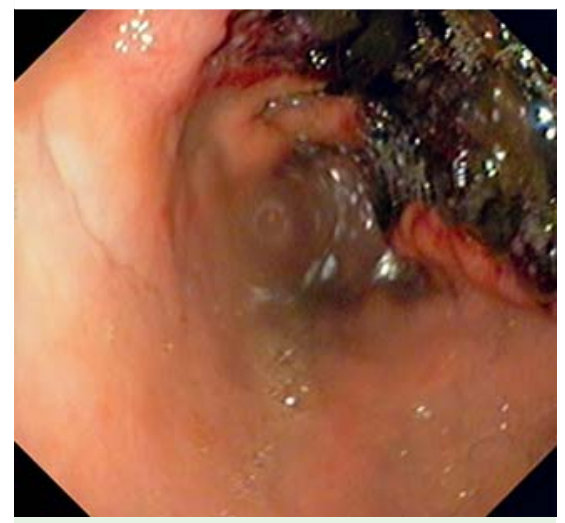

Fig. 4 While the former ulcer was almost healed, a deep complex ulcer, covered with a giant clot and filling half of the distal antrum, was observed during endoscopy $48 \mathrm{~h}$ later, due to re-bleeding. for 1 week. A follow-up endoscopy 3 months later showed full resolution of the lesion.

Several case reports in the early 1990s highlighted the risk of extensive gastrointestinal necrosis following sclerosant plus epinephrine injection for bleeding ulcers [1 -4]. Interestingly, spleen infarction has been recently reported following highvolume epinephrine injection in a gastric bleeding vessel, without sclerosants [5]. Inadvertent intra-arterial injection may result in either spasm or thrombosis leading to subsequent tissue ischemia or necrosis. Endoscopists should be aware of this rare complication. Lower volumes of sclerotherapy, lower speed of injection, avoiding the visible vessel and using alternative endoscopic therapies (clips, argon plasma coagulation) may minimize its occurrence.

Endoscopy_UCTN_Code_CCL_1AZ_2AC

\section{Competing interests: None}

\section{J. Molina-Infante ${ }^{1}$, M. Fernandez-Ber- mejo $^{1}, \mathbf{G}$. Vinagre-Rodríguez ${ }^{1}$}

Department of Gastroenterology, Hospital San Pedro de Alcantara, Caceres, Spain

\section{References}

1 Loperfido S, Patelli G, La Torre L. Extensive necrosis of gastric mucosa following injection therapy for bleeding peptic ulcer. Endoscopy 1990; 22: 285-286

2 Chester JF, Hurley PR. Gastric necrosis: a complication of endoscopic sclerosis for bleeding peptic ulcer. Endoscopy 1990; 22: 287

3 Dell'Abate P, Sppagiari L, Carboynani $P$ et al. An unusual complication of sclerotherapy. Endoscopy 1991; 23: 352 - 353

4 Cappelli J, Dryjski J, Rahier I et al. Another severe complication of sclerotherapy for bleeding peptic ulcer. Endoscopy 1993; 25 : 431-432

5 Oida T, Mimastu K, Kawasaki A et al. Splenic infarction and abscess after endoscopic injection of hypertonic saline-epinephrine solution administered for bleeding gastric ulcer. Endoscopy 2008; 40 (Suppl 2): E239

Bibliography

Dol $10.1055 / \mathrm{s}-0030-1256352$

Endoscopy 2011; 43: E191

(c) Georg Thieme Verlag KG Stuttgart · New York . ISSN 0013-726X

\section{Corresponding author}

Dr. J. Molina-Infante

Unit of Gastroenterology

Hospital San Pedro de Alcantara

Pablo Naranjo s/n 10003

Caceres

Spain

xavi_molina@hotmail.com 